\title{
Pretransplant Serum Fibrinogen Level may be a Predictive Marker on Chronic Graft-Versus-Host Disease (cGVHD) in Patients Having Undergone Allogeneic Hematopoietic Stem Cell Transplantation (allo-HSCT)
}

\author{
Neslihan MANDACI SANLI, Muzaffer KEKLIK1, Ali UNAL
}

Erciyes University Faculty of Medicine, Department of Hematology and Bone Marrow Transplant Center, Kayseri, TURKEY

\begin{abstract}
Inflammatory processes play an important role in the pathophysiology of cGVHD. Serum fibrinogen is a proinflammatory protein with a wide range of functions in inflammation. But its role in GVHD is unclear. The aim of this study was to evaluate the predictive impact of pre-transplantation fibrinogen levels on cGVHD in allo-HSCT recipients. We retrospectively analyzed 249 patients with hematologic diseases undergoing allo-HSCT from 10/10 HLA-matched donors. Serum high fibrinogen levels at the time of HSCT (day 0) were significantly associated with cGVHD development in univariate analyses (OR 2.01, $p=0.012)$ and multivariate analyses $(O R 1.003, p=$ 0.037 ). There was no significant association between fibrinogen levels and overall survival, disease-free survival and, acute GVHD ( $p>$ 0.05). This is the first report demonstrating the association between high fibrinogen levels and increased cGVHD occurrence.Further studies are warranted and may identify the efficacy of fibrinogen as a predictive marker on cGVHD in allo-HSCT recipients.
\end{abstract}

Keywords: Allogeneic Hematopoietic Stem Cell Transplantation, Fibrinogen, Inflammation, Chronic Graft-Versus-Host Disease

\section{INTRODUCTION}

Allogeneic hematopoietic stem cell transplantation (allo-HSCT) remains a cornerstone curative therapy for high-risk hematological malignancy and severe immune deficiencies. ${ }^{1}$ Although this therapeutic approach has demonstrated good rates of success for disease eradication, life-threatening complications such as severe acute graft-versushost disease (aGVHD) or chronic graft-versus-host disease (cGVHD) and infections remain as major problems after HSCT. ${ }^{2-4}$

cGVHD is a multisystem inflammatory disease characterized by tissue fibrosis. The treatment out- come of allogeneic hematopoietic stem cell transplantation (HSCT) for hematological disorders was determined by two major factors: transplantrelated morbidity or mortality (TRM) and disease relapse. cGVHD represents the major cause of procedural morbidity and nonrelapse mortality.,

Depending on the type of transplantation, patient age, immunosuppression, and underlying disorders $35-50 \%$ of transplanted patients develop cGVHD. ${ }^{7-10}$ Patients developing severe cGVHD have a mortality risk of about $25-35 \%$ due to immunemediated specific organ damage and/or concomitant infections. ${ }^{8,11-14}$ 
Because of this, doctors try to reduce the occurrence and severity of GVHD before and after transplantation and take every precaution to prevent GVHD. Predicting patients at high risk of developing cGVHD might allow early therapeutic interventions and, thereby, prevent long-term complications.

Serum fibrinogen level may be a predictive marker for the risk of occurrence of cGVHD.

Fibrinogen is a soluble 340-kDa glycoprotein synthesized by hepatocytes in the liver ${ }^{15}$ and one of the most important coagulation factors. In pathological conditions, such as after injury, or disease associated with vascular disruption, infection, or inflammation, the blood concentration of fibrinogen increases severalfold. ${ }^{16}$ It is a modest acute-phase reactant. So, fibrinogen is a pro-inflammatory protein. Coagulation factors play important biological roles not only in hemostasis but also in reproduction, tissue repair, and inflammatory responses related to infection or disease. ${ }^{17}$

Evidence shows that there is some connection between fibrinogen and the development of inflammation. ${ }^{17}$ And chronic inflammation is a risk factor in the occurrence of cGVHD. ${ }^{18}$ Additionally, IL-6 is a pleiotropic cytokine that is released after the induction of macrophage activation by fibrinogen. ${ }^{19} \mathrm{IL}-6$ signaling results in phosphorylation of STAT3, which is critical for the generation of cGVHD. ${ }^{20,21}$

To date, no studies have demonstrated the predictive value of serum fibrinogen levels on cGVHD in patients undergoing allo-HSCT. We, therefore, retrospectively analyzed the pretransplant fibrinogen levels to investigate the relationship between elevated fibrinogen levels and cGVHD and to evaluate the predictive value of fibrinogen on cGVHD.

\section{PATIENTS and METHODS}

\section{Patients}

The records of 249 patients who underwent alloHSCT from 10/10 HLA-matched donors due to hematological diseases at Erciyes University Hematology Transplant Center, between the years of 2003-2016, were retrospectively reviewed. Pre- transplantation (the day of HSCT, day 0) serum fibrinogen was available for 249 patients. The cutoff value was $350 \mathrm{mg} / \mathrm{dl}$. At our institution, serum fibrinogen levels between $180-350 \mathrm{mg} / \mathrm{dl}$ are considered within the normal range.

Patients were divided into 2 groups; patients with pretransplant fibrinogen levels lower than $\leq 350$ $\mathrm{mg} / \mathrm{dl}$ and higher than $350 \mathrm{mg} / \mathrm{dl}$. This study was approved by the local ethics committee of Erciyes University (Approval number: 2021/399).

\section{Transplantation Procedures and Prophylaxis Strategy:}

HSCT was performed according to standard transplantation procedures. Myeloablative conditioning (MAC) consisted of cyclophosphamide/total body irradiation (TBI) or cyclophosphamide/busulfan. Reduced-intensity conditioning (RIC) consisted of fludarabine/busulfan, fludarabine/melphalan, or fludarabine/low dose TBI. For GVHD prophylaxis, patients received methotrexate plus cyclosporine A. Patients with a matched unrelated donor additionally received anti-thymocyte globulin (ATG).

In the first 4 weeks of the post-transplant period, antibacterial (moxifloxacin $1 \times 400 \mathrm{mg} /$ day) and antiviral (valacyclovir $1 \times 500 \mathrm{mg} /$ day) prophylactic regimens were administered. For antifungal prophylaxis, fluconazole $2 \times 200 \mathrm{mg} /$ day was given in the post-transplant period until the 75 th day following the transplant. Trimethoprim and sulfamethoxazole treatment were given at a dose of $160 \mathrm{mg}$ and $800 \mathrm{mg}$, respectively, twice a day, twice weekly for pneumocystis jirovecii prophylaxis after the engraftment was achieved until 180. Patients were followed by weekly visits for the first month and biweekly for 3 months.

\section{Definition of Transplant-Related Variables}

For transplantation-associated risk stratification patients with acute leukemia in first or second complete remission (CR) and patients with myelodysplastic syndrome (MDS) were considered to be a standard risk. ${ }^{22}$ All other patients were graded as being at high risk. Gender mismatch between donor and host was graded as high risk in the case of female donors with male recipients, and all oth- 
Table 1. Patient characteristics

\begin{tabular}{|c|c|}
\hline Variables & n (\%) \\
\hline Age, years $(<40 / \geq 40)$ & $174(69.9) / 75(30.1)$ \\
\hline Gender (male / female) & $153(61.4) / 96(38.6)$ \\
\hline \multicolumn{2}{|l|}{ Diagnosis } \\
\hline Acute leukemia & $175(70.3)$ \\
\hline Lymphoproliferative diseases & $17(6.8)$ \\
\hline Other diseases & $57(22.9)$ \\
\hline Sex mismatch (standard risk/high risk) & $183(73.5) / 66(26.5)$ \\
\hline Risk group (standard risk / high risk) & $166(66.7) / 83(33.3)$ \\
\hline \multicolumn{2}{|l|}{ Time to transplant } \\
\hline (< 12 months $/ \geq 12$ months & $184(73.9) / 65(26.1)$ \\
\hline \multicolumn{2}{|l|}{ Conditioning regimen } \\
\hline MAC & $168(72.4)$ \\
\hline $\mathrm{RIC}$ & $64(27.6)$ \\
\hline \multicolumn{2}{|l|}{ HLA matched } \\
\hline Related & $219(82)$ \\
\hline Unrelated & $3(1.1)$ \\
\hline CD 34+count, 106/kg, median (range) & $7.1(2.7-16)$ \\
\hline \multicolumn{2}{|l|}{ Fibrinogen level at HSCT } \\
\hline Median in mg/dl (range) & $311(7.1-1003)$ \\
\hline \multicolumn{2}{|c|}{ Neutrophil engraftment, d, median (range) 15 (8-61) } \\
\hline Missing & $14(5.6)$ \\
\hline \multicolumn{2}{|c|}{ Platelet engraftment, $d$, median (range) 11 (4-64) } \\
\hline Missing & $12(4.8)$ \\
\hline Infection (yes) & $185(74.3)$ \\
\hline Acute GVHD (yes) & $35(14.1)$ \\
\hline Chronic GVHD (yes) & 83 (33.3) \\
\hline GVHD (yes) & $112(45)$ \\
\hline DFS, d, median (range) & $365(4-4320)$ \\
\hline OS, d, median (range) & $520(4-4320)$ \\
\hline Peri-transplant mortality (yes) & $7(2.8)$ \\
\hline Early-transplant mortality (yes) & $26(10.4)$ \\
\hline
\end{tabular}

DFS: Disease-Free Survival; GVHD: Graft-Versus-Host Disease; HLA Human Leukocyte Antigen; OS: Overall Survival; d: day; MAC: Myeloablative; Conditioning; RIC: Reduced Intensity Conditioning

ers were considered a standard risk. ${ }^{23}$ GVHD was graded according to standard clinical criteria. ${ }^{24,25}$

\section{Statistical Analysis}

In statistical analysis, we used the Mann-Whitney $\mathrm{U}$ test for continuous variables between the two groups. Pearson Chi-Square test and Fisher Freeman Halton test were used for comparison of cat- egorical data. Survival and mortality probabilities were estimated using the Kaplan-Meier method, and comparisons were performed using the logrank test. Moreover, univariate and multivariate logistic regression analyses were applied to identify the most significant risk factors on GVHD. Also, odds ratios were given with $95 \%$ confidence intervals (CIs). $\mathrm{P}<0.05$ was considered statistically significant.

\section{RESULTS}

\section{Patients Characteristics}

Patients' characteristics are listed in Table 1. There were 249 patients enrolled in our study. 153 (61.4\%) of the patients were male, and 96 (38.6\%) were female. One hundred seventy-four patients (69.8\%) were below the age of 40, $75(30.1 \%)$ were above 40. Most patients were transplanted for acute leukemia $(70.3 \%)$, with fewer patients transplanted for lymphoproliferative diseases (6.8\%), myelodysplastic syndrome (2\%), and other diseases (20.9\%). For risk classification; 83 patients (33.3\%) were defined as high versus 166 (66.7\%) standard risk.

Most patients received a myeloablative conditioning regimen $(72.4 \%)$. Two hundred nineteen patients were transplanted from 10/10-HLA-matched related donors while three patients had an unrelated 10/10-HLA-matched donor. The time-totransplant period was less than 12 months in 184 (73.9\%) patients and more than 12 months in 65 (26.1\%) of the patients. The median time for neutrophil engraftment was 15 days (range, 8-61 days) and 11.00 days (range, 4-64 days) for platelet engraftment. The median level of fibrinogen level at the time of HSCT was $311 \mathrm{mg} / \mathrm{dl}$ (range, 7.1-1003 $\mathrm{mg} / \mathrm{dl})$.

We divided these patients into two groups according to the level of plasma fibrinogen. The concentration of plasma fibrinogen greater than $350 \mathrm{mg} /$ dl was described as hyperfibrinogenemia. Applying this cutoff value to these patients, 87 (34.9\%) patients had a higher level of fibrinogen while 162 (65.1\%) patients had fibrinogen levels below the cut-off. 


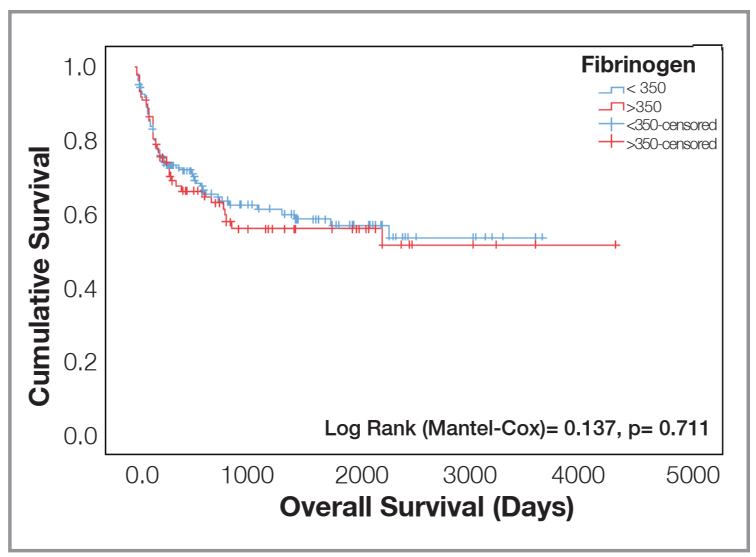

Figure 1. Patients with pre-transplant serum fibrinogen levels $>350 \mathrm{mg} / \mathrm{dl}$ did not have a significant difference in OS compared with those with pre-transplant serum fibrinogen levels $\leq$ $350 \mathrm{mg} / \mathrm{dl}(p=0.71)$

In the posttransplant evaluation; infections were the leading complication in the recipients 185 (74.3\%) of the patients had at least $\geq 1$ episode of infectious events. GVHD was the second common complication in the post-transplant period. A total of $35(14.1 \%)$ patients had acute GVHD while chronic GVHD was diagnosed in $83(33.3 \%)$ of the patients. A total of 94 patients (37.8\%) died during the posttransplant follow-up. A total of 26 patients $(10.4 \%)$ died in the first 30 days after transplantation (early transplant mortality), while 7 patients $(2.8 \%)$ died within the first 100 days after transplantation (peritransplant mortality). Fifty-three patients $(21.3 \%)$ relapsed in the posttransplant period. OS and DFS were 520 days (range, 4 - 4320) and 365 days (range, 4 - 4320), respectively.

\section{The Association of OS and DFS with Elevated Serum Fibrinogen Levels}

Pretransplant elevated fibrinogen levels were not significantly associated with the OS $(\mathrm{p}=0.71)$ and DFS ( $\mathrm{p}=0.61)$ (Figüre 1 and Figüre 2).

The association of elevated serum fibrinogen levels prior to transplantation with GVHD: Univariate and multivariate analysis showed that patients with elevated serum fibrinogen levels $>350 \mathrm{mg} /$ dl displayed significantly increased development of chronic cGVHD compared with those whose value was $\leq 350 \mathrm{mg} / \mathrm{dl}$ (univariate $\mathrm{OR}=2.01,95 \%$ CI: $1.16-3.47, \mathrm{p}=0.012$; multivariate $\mathrm{OR}=1.003$, 95\% CI: 1 - 1.006, $\mathrm{p}=0.037)$. Multivariate, as well

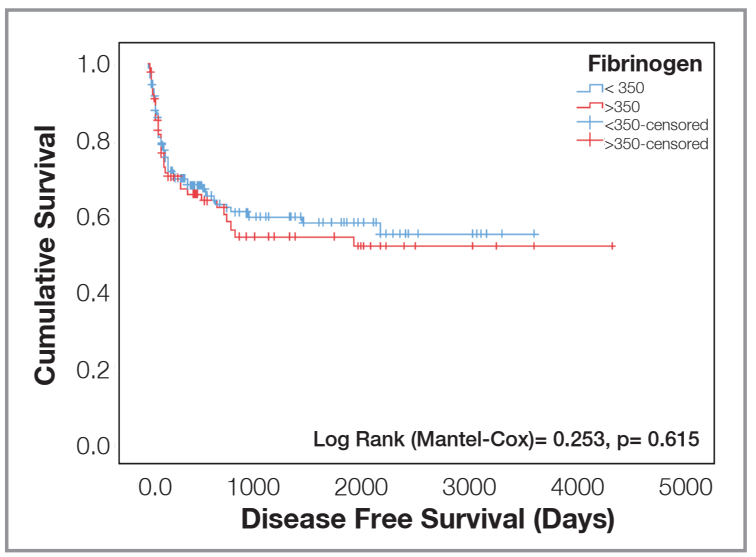

Figure 2. Patients with pre-transplant serum fibrinogen levels $>350 \mathrm{mg} / \mathrm{dl}$ did not have a significant difference in DFS compared with those with pretransplant serum fibrinogen levels $\leq$ $350 \mathrm{MG} / \mathrm{DL}(\mathrm{p}=0.61)$

as univariate analyses, are shown in Table 2 . We concluded that elevated serum fibrinogen levels prior to allo-SCT are an independent risk factor for cGVHD.

Risk factors for cGVHD in the univariate analysis were sex mismatch [patients with high risk had significantly increased cGVHD risk compared to with standard risk $(\mathrm{OR}=2.33,95 \% \mathrm{CI}: 1.14-4.79, \mathrm{p}=$ $0.02)$ ], other diseases [patients with other diseases had a lower risk compared with patients with acute leucemia (OR 0.43, 95\% CI: 0.20 - 0.88, $\mathrm{p}=0.025)$ ], time to transplant interval [patients who had undergone allo-HSCT more than 12 months from diagnosis ( $\geq 12$ months) had lower risk compared to with those who had undergone allo-HSCT within 12 months from diagnosis (< 12 months) (OR 0.45 , 95\% CI: $0.23-0.88, \mathrm{p}=0.021)$ ], risk status [patients with high transplantation associated risk had significantly increased cGVHD risk compared to with standard transplantation associated risk (OR 1.79, 95\% CI: 1.03 - 3.10; $\mathrm{p}=0.038)$ ], conditioning regimens [patients who have been treated with RIC regimen a had lower risk compared with patients who have been treated with MAC regimen $(\mathrm{OR}=$ $0.22,95 \%$ CI: $0.10-3.10 ; p=0.49)$ ].

Risk factors for cGVHD in the multivariate analysis were conditioning regimens [patients who have been treated with RIC regimen had a lower risk compared with patients who have been treated with MAC regimen $(\mathrm{OR}=0.34,95 \%$ CI: $0.14-0.8 ; \mathrm{p}=$ $0.013)$ ], age [patients who were older than 40 years 
International Journal of Hematology and Oncology

\begin{tabular}{|c|c|c|c|c|}
\hline \multirow[t]{3}{*}{ Variables } & \multicolumn{4}{|c|}{ cGVHD } \\
\hline & \multicolumn{2}{|c|}{ Univariate } & \multicolumn{2}{|c|}{ Multivariate } \\
\hline & OR (95\% Cl) & $p$ & OR (95\% Cl) & p \\
\hline \multicolumn{5}{|l|}{ Age, years } \\
\hline$<40$ & 1.00 & & & \\
\hline$\geq 40$ & $1.65(0.94-2.90)$ & 0.08 & & \\
\hline \multicolumn{5}{|l|}{ Gender } \\
\hline male & 1.00 & & & \\
\hline female & $1.08(0.62-1.85)$ & 0.78 & & \\
\hline \multicolumn{5}{|l|}{ Diagnosis } \\
\hline Acute leukemia & 1.00 & & & \\
\hline Other diseases & $0.43(0.20-0.89)$ & 0.25 & & \\
\hline MDS & $1.07(1.17-6.59)$ & 0.93 & & \\
\hline $\begin{array}{l}\text { Lymphoproliferative } \\
\text { diseases }\end{array}$ & $0.34(0.0 .09-1.24)$ & 0.10 & & \\
\hline \multicolumn{5}{|l|}{ Sex mismatch } \\
\hline Standard risk & 1.00 & & & \\
\hline High risk & $2.04(0.14-3.65)$ & $0.01^{*}$ & $2.33(1.14-4.79)$ & 0.08 \\
\hline \multicolumn{5}{|l|}{ Disease status } \\
\hline Standard risk & 1.00 & & & \\
\hline High risk & $1.79(1.03-3.10)$ & $0,038^{*}$ & $1.78(0.93-3.44)$ & 0.08 \\
\hline \multicolumn{5}{|l|}{ Conditioning regimen } \\
\hline RIC & 1.00 & & & \\
\hline MAC & $0.22(0.10-0.49)$ & $<0,001^{\star \star}$ & $0.34(0.14-0.8)$ & $0.01^{*}$ \\
\hline \multicolumn{5}{|l|}{ Time to transplant } \\
\hline$<12$ months & 1.00 & & & \\
\hline$\geq 12$ months & $0.45(0.23-0.88)$ & $0.021^{*}$ & & \\
\hline \multicolumn{5}{|l|}{ Serum fibrinogen level } \\
\hline$\leq 350$ & 1.00 & & & \\
\hline$>350$ & $2.01(1.16-3.47)$ & $0.012^{*}$ & $1.003(1-1.006)$ & $0.037^{\star}$ \\
\hline Neutrophil engraftment & $1.01(0.96-1.06)$ & 0.58 & & \\
\hline Platelet engraftment & $1.01(0.96-1.06)$ & 0.53 & & \\
\hline CD34+ Count & $0.95(0.83-1.09)$ & 0.51 & & \\
\hline Infection (yes/no) & $1.89(0.99-3.64)$ & 0.054 & & \\
\hline
\end{tabular}

had increased cGVHD risk compared with those who were younger than 40 years (OR 1.03, 95\% CI: $1-1.05 ; \mathrm{p}=0.021)]$.

The parameters of gender, presence of infection, relapse, and the number of totals infused CD34+ cells showed no significant effect on cGVHD (p> $0.05)$.
In univariate analysis, the development of acute GVHD was not significantly associated with elevated serum fibrinogen levels (OR 0.6, 95\% CI: $0.26-1.35 ; \mathrm{p}=0.22$ ).

\section{DISCUSSION}

To the best of our knowledge, this is the first study evaluating the predictive impact of pretransplant 
plasma fibrinogen levels on cGVHD occurrence in patients undergoing allo- HSCT. Our results suggest that elevated plasma fibrinogen levels before allo-HSCT are associated with cGVHD development but not with poorer PFS and OS. Therefore, plasma fibrinogen levels may be useful as a predictive marker for $\mathrm{cGVHD}$.

Previous reports in cancer patients indicated that plasma fibrinogen levels are of prognostic significance in several solid malignancies including endometrial and ovarian, ${ }^{26,27}$ renal cell, ${ }^{28}$ esophageal, ${ }^{29}$ and hepatocellular ${ }^{30}$ and non-small cell lung cancer, ${ }^{31}$ and in hematologic malignancies such as $\mathrm{AML}^{32,33}$ and $\mathrm{DBBH}{ }^{34}$ These findings in solid tumors and hematologic tumors led us to explore the impact of elevated plasma fibrinogen levels on cGVHD development in patients undergoing allohsct.

A possible explanation is that fibrinogen is a wide spectrum of functions in inflammation. ${ }^{17}$ Inflammatory processes have been reported to play an important role in the pathophysiology of cGVHD. The pathogenesis of cGVHD is a complex process that involves early inflammation and tissue injury, chronic inflammation and, aberrant tissue repair and fibrosis. ${ }^{18,35}$

In most cases, the proinflammatory functions of fibrin (ogen) and its derivative peptides are associated with their ability to bind to and activate a wide range of immune cells through distinct ligand-receptor interactions. These receptors are expressed on dendritic cells, monocytes, macrophages, neutrophils, and some B cells. ${ }^{17,36-38}$ Fibrinogen signals either directly or indirectly through a number of receptors, adhesion molecules, and cell- surface proteins that are involved in inflammatory processes. Several chemokines and cytokines, such as IL6, IL8, TNF- $\alpha$, macrophage inflammatory protein-1 (MIP-1) $\alpha$ and $\beta$, matrix metalloproteinase (MMP) $)^{1,39,40}$ release after the induction of macrophage activation by fibrinogen. Classical IL-6 signaling results in phosphorylation of STAT3, which is critical for the generation of cGVHD. ${ }^{20,21,41}$

Macrophages are also a source of transforming growth factor (TGF) beta (TGFb), TNF a, IL-1b, platelet-derived growth factor (PDGFR), and matrix metalloproteinases, with an ensuing cascade of fibrosis. ${ }^{35,41}$ TGF-B released via macrophage stimulation by fibrinogen, indisputably, is one of the key drivers of fibrosis and inflammation. Its role in cGVHD as a profibrotic cytokine is that can directly induce the differentiation of fibroblasts into collagen-secreting myofibroblasts. In clinical cGVHD lesions, macrophages are abundant and are found in close proximity to collagen-producing myofibroblasts. ${ }^{42,44}$

Another possible explanation is that fibrinogen acts as an important coagulation factor, and its elevated levels can lead to imbalances in the body's coagulation and fibrinolytic systems, resulting in platelet aggregation and thrombin generation. Thrombin in turn leads to increased conversion of fibrinogen to fibrin. Peptides released as a part of fibrin formation can act as chemoattractants for leukocytes and thus independently modulate inflammatory responses..$^{17,35,45}$ Activated platelets also release growth factors such as platelet-derived growth factor (PDGFR), a potent chemoattractant for inflammatory cells, and transforming growth factor-B1(TGFB-1), which stimülates extracellular matrix synthesis by local fibroblasts. Consequently, any prolonged disturbance in the coagulation cascade can lead to fibrosis. ${ }^{35,46}$

In a study on autologous hematopoietic stem cell transplantation (ASCT), Ogura and Nakazato ${ }^{47}$ showed that pretransplant hyperfibrinogenemia was associated with poor survival in patients with lymphoma who underwent ASCT (5-year OS: p< $0.001)$. On the other hand, they did not find any relationship between the pretransplant hyperfibrinogenemia and survival in multiple myeloma patients (5-year OS p=0.17). But their study was based on a small-sized analysis (47 patients with malignant lymphoma and 57 patients with multiple myeloma). In addition, their study was related to autologous hematopoietic stem cell transplantation.

In another study involving acute myeloid leukemia (AML) patients who did not undergo allo-HSCT, Berger et al. ${ }^{32}$ showed that high fibrinogen levels at diagnosis of AML were associated with adverse OS and DFS ( $p=0.0009$ and $p=0.0076)$. However, the patients consisted of newly diagnosed AML patients. 
This study has a number of limitations. First, this study was a retrospective, single-center study. Additional prospective multicenter studies are required to confirm the real association between fibrinogen and post-transplant GVHD. Second, In our laboratory devices, serum fibrinogen levels were between 100-350 mg/dl. We determined the cut-off level for abnormality of fibrinogen levels as $>350 \mathrm{mg} / \mathrm{dl}$. The cut off value for fibrinogen has varied in different studies. For example, While the cut-off fibrinogen value was $376 \mathrm{mg} / \mathrm{dl}$ in a study in lymphoma patients who underwent auto$\mathrm{HSCT},{ }^{47}$ the cut-off value was $410 \mathrm{mg} / \mathrm{dl}$ in a study involving newly diagnosed AML patients. ${ }^{32}$

Consequently, the results of this study suggest that there is a rationale for adequately powered prospective studies to confirm the predictive significance of fibrinogen levels as a biomarker for cGVHD development in allo-HSCT recipients. We propose that plasma fibrinogen levels may become a useful biomarker on the prediction of the development of cGVHD, particularly because of the low associated cost and easy accessibility.

\section{REFERENCES}

1. Markey KA, MacDonald KP, Hill GR. The biology of graftversus-host disease: experimental systems instructing clinical practice. Blood 124: 354-362, 2014.

2. Holler E. Risk assessment in haematopoietic stem cell transplantation: GvHD prevention and treatment. Best Pract Res Clin Haematol 20: 281-294, 2007.

3. Fuji S, Kapp M, Einsele H. Challenges to preventing infectious complications, decreasing re-hospitalizations, and reducing cost burden in long-term survivors after allogeneic hematopoietic stem cell transplantation. Semin Hematol 49: 10-14, 2012.

4. Wingard JR, Hsu J, Hiemenz JW. Hematopoietic stem cell transplantation: an overview of infection risks and epidemiology. Hematol Oncol Clin North Am 25: 101-116, 2011.

5. Flowers ME, Martin PJ. How we treat chronic graft-versushost disease. Blood 125: 606-615, 2015.

6. Martin PJ, Counts Jr GW, Appelbaum FR, et al. Life expectancy in patients surviving more than 5 years after hematopoietic cell transplantation. J Clin Oncol 28:1011-1016, 2010.

7. Liu YC, Chien SH, Fan NW, et al. Prognostic factors on the Graft-versus-Host disease-free and relapse-free survival after adult allogeneic hematopoietic stem cell transplantation. Stem Cells Int 2016: 1-9, 2016.
8. Finke J, Schmoor C, Bethge WA, et al. Prognostic factors affecting outcome after allogeneic transplantation for hematological malignancies from unrelated donors: results from a randomized trial. Biol Blood Marrow Transplant 18: 17161726, 2012.

9. Kolb HJ. Graft-versus-leukemia effects of transplantation and donor lymphocytes. Blood 112: 4371-4383, 2008.

10. Ferrara JL, Levine JE, Reddy P, Holler E. Graft-versus-host disease. Lancet 373: 1550-1561, 2009.

11. Holler E, Kolb HJ, Greinix H, et al. Bleeding events and mortality in SCT patients: a retrospective study of hematopoietic SCT patients with organ dysfunctions due to severe sepsis or GVHD. Bone Marrow Transplant 43: 491-497, 2009.

12. Jacobsohn DA, Kurland BF, Pidala J, et al. Correlation between NIH composite skin score, patient reported skin score and outcome: results from the chronic GVHD Consortium. Blood 120: 2545-2552, 2012.

13. Greinix HT, Loddenkemper C, Pavletic SZ, et al. Diagnosis and staging of chronic graft-versus-host disease in the clinical practice. Biol Blood Marrow Transplant 17: 167-175, 2011.

14. Kroger N, Solano C, Wolschke C, et al. Antilymphocyte globulin for prevention of chronic graft-versus-host disease. N Engl J Med 374: 43-53, 2016.

15. Weisel JW. Fibrinogen and fibrin. Adv Protein Chem 70: $247-$ 299, 2005.

16. Adams RA, Passino M, Sachs BD, et al. Fibrin mechanisms and functions in nervous system pathology. Mol Interv 4: 163176, 2004.

17. Davalos D, Akassoglou K. Fibrinogen as a key regulator of inflammation in disease. Semin Immunopathol 34:43-62, 2012.

18. Cooke KR, Luznik L, Sarantopoulus S, et al. The Biology of Chronic Graft-versus- Host disease: A task force report from the National Institutes of Health Consensus Development Project on Criteria for Clinical Trials Graft-versus-Host Disease. Biol Blood Marrow Transplant 23: 211-234, 2017.

19. Scheller J, Chalaris A, Schmidt-Arras D, RoseJohn S. The pro- and anti-inflammatory properties of the cytokine interleukin-6. Biochim Biophys Acta 1813: 878-888, 2011.

20. Radojcic V, Pletneva MA, Yen H-R, et al. STAT3 signaling in CD4+ T cells is critical for the pathogenesis of chronic sclerodermatous graft-versus-host disease in a murine model. $J$ Immunol 184: 764-774, 2010.

21. Flynn R, Paz K, Du J, et al. Targeted Rho-associated kinase 2 inhibition suppresses murine and human chronic GVHD through a Stat3-dependent mechanism. Blood 127: 21442154, 2016.

22. Armand P, Gibson CJ, Cutler $\mathrm{C}$ et al. A disease risk index for patients undergoing allogeneic stem cell transplantation. Blood 120: 905-913, 2012. 
23. Nannya $Y$, Kataoka $K$, Hangaishi $A$, et al. The negative impact of female donor/male recipient combination in allogeneic hematopoietic stem cell transplantation depends on disease risk. Transpl Int 24:469-476, 2011.

24. Przepiorka D, Weisdorf D, Martin P, et al. Consensus conference on acute GVHD grading. Bone Marrow Transplant 15: 825-828, 1995.

25. Lee SJ, Vogelsang G, Flowers ME. Chronic Graft-VersusHost disease. Biol Blood Marrow Transplant 9: 215-233, 2003.

26. Seebacher V, Polterauer S, Grimm C, et al. The prognostic value of plasma fibrinogen levels in patients with endometrial cancer: a multi-centre trial. Br J Cancer 102: 952-956, 2010.

27. Polterauer S, Grimm C, Seebacher V, et al. Plasma fibrinogen levels and prognosis in patients with ovarian cancer: a multicenter study. Oncologist 14: 979-985, 2009.

28. Pichler M, Hutterer GC, Stojakovic T, et al. High plasma fibrinogen level represents an independent negative prognostic factor regarding cancer-specific, metastasis-free, as well as overall survival in a European cohort of non-metastatic renal cell carcinoma patients. Br J Cancer 109: 1123-1129, 2013.

29. Matsuda S, Takeuchi H, Fukuda K, et al. Clinical significance of plasma fibrinogen level as a predictive marker for postoperative recurrence of esophageal squamous cell carcinoma in patients receiving neoadjuvant treatment. Dis Esophagus 27: 654-661, 2014.

30. Kinoshita A, Onoda H, Imai N, et al. Elevated plasma fibrinogen levels are associated with a poor prognosis in patients with hepatocellular carcinoma. Oncology 85: 269-277, 2013.

31. Kim KH, Park TY, Lee JY et al. Prognostic significance of initial platelet counts and fibrinogen level in advanced non-small cell lung cancer. J Korean Med Sci 29: 507-511, 2014.

32. Berger MD, Heini AD, Seipel K, et al. Increased fibrinogen levels at diagnosis are associated with adverse outcome in patients with acute myeloid leukemia. Hematol Oncol 35: 789-796, 2017

33. Dai K, Zhang Q, Li Y, et al. Plasma fibrinogen levels correlate with prognosis and treatment outcome in patients with nonM3 acute myeloid leukemia. Leuk Lymphoma 60:1503-1511, 2019.

34. Niyu JY, Tian T, Zhu HY, et al. Hyperfibrinogenemia is a poor prognostic factor in diffuse large B cell lymphoma. Annal Hematol 97:1841-1849, 2018

35. Wynn TA, Ramalingam TR. Mechanisms of fibrosis: Therapeutic translation for fibrotic disease. Nat Med 18: 10281040, 2012

36. Solovjov DA, Pluskota E, Plow EF. Distinct roles for the alpha and beta subunits in the functions of integrin alphaMbeta2. J Biol Chem 280: 1336-1345, 2005.

37. Scheller J, Chalaris A, Schmidt-Arras D, RoseJohn S. The pro- and anti-inflammatory properties of the cytokine interleukin-6. Biochim Biophys Acta 1813: 878-888, 2011.
38. Nham SU. Characteristics of fibrinogen binding to the domain of CD11c, an alpha subunit of p150,95. Biochem Biophys Res Commun 264: 630-634,1999.

39. Smiley ST, King JA, Hancock WW. Fibrinogen stimulates macrophage chemokine secretion through toll-like receptor 4. J Immunol 167: 2887-2894, 2001.

40. Hodgkinson CP, Patel K, Ye S. Functional Toll-like receptor 4 mutations modulate the response to fibrinogen. Thromb Haemost 100: 301-307, 2008.

41. MacDonald KPA, Blazar BR, Hill GR. Cytokine mediators of chronic graft-versus- host disease. The Journal of Clinical Investigation 127: 2452-2463, 2017.

42. Verrecchia F, Mauviel A. Transforming growth factor- $\beta$ and fibrosis. World J. Gastroenterol 13: 3056-3062, 2007.

43. Brüggen MC, Klein I, Greinix H, et al. Diverse T-cell responses characterize the different manifestations of cutaneous graftversus-host disease. Blood 123: 290-299, 2014.

44. Melino M, Gadd VL, Alexander KA, et al. Spatiotemporal characterization of the cellular and molecular contributors to liver fibrosis in a murine hepatotoxic-injury model. Am J Pathol 186: 524-538, 2016.

45. Skogen WF, Senior RM, Griffin GL, Wilner GD. Fibrinogenderived peptide B beta $1-42$ is a multidomained neutrophil chemoattractant. Blood 71: 1475-1479, 1988.

46. Chambers RC. Procoagulant signalling mechanisms in lung inflammation and fibrosis: novel opportunities for pharmacological intervention? Br. J. Pharmacol. 153: S367-S378, 2009.

47. Ogura S, Nakazato T. The Prognostic Significance of Pretransplant Plasma Fibrinogen Levels in Autologous Hematopoietic Stem Cell Transplantation. Transplant Proc 53: 405407, 2021.

\section{Correspondence:}

\section{Dr. Neslihan MANDACI SANLI}

Erciyes Universitesi Tip Fakultesi

Hematoloji Anabilim Dali ve Kemik lligi Nakli Merkezi KAYSERI / TURKEY

Tel: (+90-505) 7007392

e-mail: ortoforia@hotmail.com

\section{ORCIDs:}

Neslihan Mandaci Sanli

0000-0002-6298-9884 Muzaffer Keklik

0000-0002-6426-5249

Ali Unal 